\title{
Positive organisational scholarship in healthcare
}

\author{
Ann Dadich and Ben Farr-Wharton
}

Welcome to an international first - a special issue dedicated to positive organisational scholarship in healthcare (POSH). Its precursor - positive organisational scholarship (POS) - is the study of that which is flourishing and life-giving (Cameron \& Spreitzer, 2012b). Since its relatively short, two-decade history, POS has achieved a robust state of legitimacy. Consider the growing wealth of POS publications (Bright \& Miller, 2013; Cameron, 2017; Cameron \& Spreitzer, 2012b; Nilsson, 2015; Quinn \& Cameron, 2019; Waters Robichau, 2017), as well as broader scrutiny about the limited value of perpetual, incremental and deficiency-focussed 'bite-sized chunks of research' (Tourish, 2019: 1). This special issue furthers POS by purposely situating it in the context of healthcare, thereby extending POS to POSH. As a helpful entrée to this special issue, we - as guest editors - address three pertinent questions; namely, what is POSH; why is it needed; and given the scholarship presented in this special issue, where to next?

\section{What is POSH?}

Coined by Professor Emeritus Liz Fulop (to our knowledge) and pursued by the Brilliance Group (a multidisciplinary collective of scholars and practitioners, which forms part of the Health Management Research Alliance), POSH is 'concerned primarily with the study of especially positive outcomes, processes, and attributes of [healthcare] organizations and their members' (Cameron, Dutton, \& Quinn, 2003b: 3). It '[has] an explicit interest in understanding and explaining flourishing in [healthcare] organizational contexts (including individuals, groups, units and whole organizations)' (Dutton \& Sonenshein, 2007: 737). It serves to direct attention to different forms of positivity that bring delight, make hearts sing and exceed expectation. In essence, it directs our attention to healthcare - and the organisational practices that enable it - which might be deemed to be brilliant. The $H$ in POSH extends to organisations within the public, private and third sectors that contribute to the social fabric. As such, POSH is not limited to conventional domains, like hospitals and general practices, but embraces mental health services, drug and alcohol services, sexual health clinics, indigenous health services, aged care facilities and virtual health services, among others.

The $P$ in POSH does not denote Pollyannaish scholarship, or blind optimism that overlooks, ignores, or worse still, whitewashes the negative aspects of healthcare. Like POS, POSH is aligned with critical theory, offering an unconventional way to examine health services, sensu lato (Cameron \& Caza, 2004; Cameron, Dutton, \& Quinn, 2003a). Like critical theory, POSH represents 'an empirical philosophy of social institutions' - it 'assumes that organization science is a social practice and as such, must give an account of itself (Steffy \& Grimes, 1986: 325). Barker Caza and Caza (2008) succinctly clarified this parallel, stating:

By rejecting the traditional deficit model approach, POS serves the critical function of challenging the status quo... In the same way that critical theorists have sought to represent the unrepresented and to challenge the 'naturalness' of the status quo... POS is trying to reorient the attention of organizational science by questioning the deficit model approach and instead emphasizing the positive processes and outcomes found in organizations. As such, it shares a countertraditional stance with critical theory (p. 24).

(c) Cambridge University Press and Australian and New Zealand Academy of Management 2020. 
Furthermore, like critical theory, $\mathrm{POSH}$ has an interest in emancipation, freeing 'researchers', the 'researched' and the organisations they represent, from the shackles that might otherwise constrain their capacity to flourish. These might include disciplinary conventions, the inequitable distribution (and use) of power, rigid organisational structures and convoluted administrative requirements, among others (Grant \& Humphries, 2006). As such, POSH recognises the elephants in the room - like the new public management of healthcare (Dadich, Collier, Hodgins, \& Crawford, 2018) - and calls into question the conditions that help and/or hinder capacity-building. To simply overlook, ignore or whitewash the elephants that healthcare personnel, patients and carers want to address would be disrespectful.

\section{Why is POSH needed?}

POSH is needed for three key reasons. First, healthcare discourse is imbalanced, largely skewed towards negative narratives. Whether you consider discourse sourced from academe, the mass media, social media, government or international organisations, trials and tribulations abound. Respectively, we read of: 'workplace bullying... burnout... and turnover... among clinical nurses' (Kim, Lee, \& Lee, 2019) as well as 'Failure[s] to report poor care' (Ion, Olivier, \& Darbyshire, 2019); 'hospital... overspending' (Campbell, 2019, para. 1), while 'Patients who require... treatment in hospital are dying unnecessarily because of the poor care they receive' (Roberts, 2017, para. 1); 'Medical Center[s] [that] treat... PATIENTS like SHT!' (Grant, 2014), complemented with images; government inquiries into patient neglect (Royal Commission into Aged Care Quality and Safety, 2019) and the abuse of 'children, young people and vulnerable adults in State and faith-based care' (Royal Commission of Inquiry, 2019, para. 1); as well as 'International Crises' - like 'The flow of refugees, the spread of communicable diseases, illegal trade and cross-border military operations' - that affect public health within several subregions (WHO (World Health Organization), 2019, para. 1). Despite this focus on the trials and tribulations of healthcare, brilliance happens (Studer Group, 2007). Yet, given this imbalance, you might be forgiven for thinking otherwise.

Second (and relatedly), negative healthcare discourse, en masse, can have considerable implications for patients and carers; healthcare personnel - be they managers, clinicians, ancillary personnel or volunteers (Brunetto, Xerri, Farr-Wharton, Shacklock, Farr-Wharton, \& Trinchero, 2016); policymakers; as well as scholars. As Dadich et al. (2015) noted:

For consumers and carers, this [negative] focus can silence their positive experiences with the care and support received... furthermore, a tainted view of health services may diminish help-seeking behaviors and subsequent access to timely care... For practitioners and their services, such pessimism may (unfairly) stereotype them as part of a systemic problem... Additionally, and perhaps more importantly, it can diminish learning opportunities and innovation... In addition to diminishing the consumer and carer's experience with health services, this has implications for policymakers who may continue to support (and fund) these [apparently negative] practices (pp. 750-751).

Akin to the implications for healthcare personnel, scholars who solely focus on trials and tribulations risk thwarting opportunities to learn and innovate - that is, they risk the advancement of scholarship (Alvesson \& Sandberg, 2012). The development of a respectable theory requires research that constructively provokes beliefs and assumptions, rather than - as per convention - merely identify gaps within the knowledge-base, which is itself largely based on prevailing beliefs and assumptions (Alvesson \& Sandberg, 2011). For instance, Alvesson and Kärreman (2011) argued for 'the active mobilization and problematization of existing frameworks' (p. 4, original italics) to develop theory. Specifically: 
Problematization means that more effort is put into thinking through what may be rethought in terms of assumptions, ideas, and the conceptualization of a particular subject matter... problematization first and foremost involves a systematic questioning of some aspects of received wisdom in the sense of dominant research perspectives and theories (but also of the subject matter itself), while at the same time offering a 'positive' or constructive formulation of interesting research questions (p. 45).

This is not an argument for a dichotomy that unhelpfully polarises negativity and positivity but rather, it is a call to explore how these critically important dynamics work together and against each other in framing the ways that health services are managed, organised, experienced and understood.

A third rationale for POSH follows a recent anecdote, suggesting a focus on the trials and tribulations of healthcare denotes importance, compassion and care. During a discussion with a clinical colleague, they suggested a study to understand and promote brilliant healthcare can trivialise patient and carer concerns. With heartfelt empathy, they indicated that discourse on positive healthcare might inadvertently imply that patients' and carers' harrowing experiences are minor and inconsequential. Each day, many patients and carers walk a tightrope, facing momentous life-or-death decisions, while struck by grief, despair and hopelessness. During this time, an invitation to consider that which brings delight, makes hearts sing and exceeds expectation might be misconstrued as impertinence. This anecdote inspires several questions - for instance, how might POSH also denote importance, compassion and care? Some suggestions are offered in this special issue.

To further and sharpen POS, this special issue draws on Cameron and Spreitzer's (2012b) insights to explore each component in healthcare. They suggested that, although the $P$ component remains the most contested, challenging and inspiring, it nonetheless has four consensual meanings. First, it denotes a unique positive orientation that prefigures 'strengths rather than weaknesses, optimism rather than pessimism, supportive rather than critical communication' (Cameron, 2008: x), even under negative circumstances. Second, it requires an affirmative bias to foster resourcefulness or create an amplifying effect for individuals and their organisations through exposure to positivity. Third, it involves virtuousness and/or the quest for human virtues that capture the highest aspirations of humankind - for instance, positively deviating from unhelpful organisational protocols might be incited by a quest for a better healthcare experience. Fourth, it encompasses the pursuit of extraordinary outcomes by identifying and explaining spectacular results, surprising outcomes, and extraordinary achievements... including those in the context of change' (Spreitzer \& Cameron, 2012: 1035-1036). This might be demonstrated by (but is not limited to) positive deviance - that is, a 'collection of behaviours that depart from the norms of a referent group, in honourable ways' (Spreitzer \& Sonenshein, 2003: 209, emphasis added), as well as manifestations of positive organisational behaviour - that is, 'positively oriented human resource strengths and psychological capacities' (Luthans, 2002: 59, emphasis added). Collectively, these four meanings reveal the positive conditions that enable individuals and organisations to flourish. The $O$ component addresses 'the positive processes and states that occur in association with organisational contexts', while $S$ reflects the pursuit of 'rigorous, systematic, and theory-based foundations for positive phenomena' (Cameron \& Spreitzer, 2012a: 2).

According to Spreitzer and Cameron (2012), advancing POS involves responding to its critics and widening its scope to encompass different contexts, including health services, as well as different voices, like those of 'nonmanagerial and nonelite populations and perspectives' (p. 1042). This suggests that those who pursue POSH should not simply be seduced by all that glitters, or by those who are privileged. Reflecting critical theory (Grant \& Humphries, 2006; Oliver, 2005), POSH recognises challenges, issues and the associated effects. As such, POSH represents a deliberate attempt to redress the scholarly preoccupation with the nonpositive, if not the negative.

Building on the relatively few pockets of studies that appear to have heeded this call (Baxter, Taylor, Kellar, \& Lawton, 2016; Braithwaite, Wears, \& Hollnagel, 2015; Brunetto et al., 2016; 
Dadich et al., 2015), this special issue positions POSH within international... high quality research across the management discipline' (Anonymous, 2019, para. 1). Assembled over 3 years, it remained connected to a forum of scholarly and pragmatic debate within the Australian and New Zealand Academy of Management (ANZAM), and a network of academics and practitioners, therein - notably, the Health Management and Organisation Special Interest Group.

The articles within this issue address the conceptualisations, methodologies and applications of POSH. For instance, Miller, Devlin, Buys, and Donoghue (2019) situated POSH in aged care a timely contribution given our ageing populations (WHO (World Health Organization), 2011), the rising demand for aged care (Conroy \& Turpin, 2016) and inquiries into 'abysmal' care (Australian Broadcasting Corporation (ABC) 7.30, 2018; Burnie, 2019; Health and Social Care Committee, \& Housing Communities and Local Government Committee, 2018).

Taking POSH beyond the public health sector, Brunetto, Dick, Xerri, and Cully (2019) used it to examine - both qualitatively and quantitatively - how an organisational development program can build positive organisational behaviour within a not-for-profit organisation. Specifically, they focused on psychological capital (or PsyCap), which encompasses: hope, optimism, self-efficacy and resilience.

Crewe (2019) and Simpson (2019) and their respective colleagues collectively drew attention to organisational capacity-building. Via an international study, Crewe and Girardi (2019) considered positive deviance among nurse managers that served to enhance positive organisational outcomes; while Simpson and Farr-Wharton (2019) empirically demonstrated how to build compassionate health services.

Finally, Kippist (2019), Dadich (2019) and their corresponding colleagues offered methodological contributions, clarifying how POSH might be conducted. Their respective contexts are particularly noteworthy, demonstrating that POSH can be respectfully conducted within poignant contexts - like renal care and palliative care - where patients and carers manage life-limiting conditions, as they are reminded of the fragility of life. Like methodological Polyfilla, they demonstrated that POSH can assume different forms to ensure it is fit-for-purpose.

\section{Where to next?}

Following this world-first special issue on $\mathrm{POSH}$, the articles therein helpfully signpost opportunities to advance it. Specifically, there is now a need for research to clarify when, how and why 'awareness and control of emotions [can] provide... the initial building blocks for building PsyCap' (Brunetto et al., 2019), particularly via longitudinal research. Given the challenge of sustaining participant involvement over long periods - especially healthcare personnel - participatory methodologies and research methods might be helpful (Palmer et al., 2019; Stewart et al., 2019). There is also a need for research to clarify how to 'embed concepts from positive psychology... into day-to-day practices... And... the 'how' of implementing a happiness-focussed initiative in aged care' (Miller et al., 2019). Equally important is research on the role of the 'paradox mindset phenomena... to better understand positive deviance', including tensions between 'positive and negative' deviance (Crewe \& Girardi, 2019). Inspired by Simpson and Farr-Wharton (2019), it would be helpful to know who should assume responsibility for 'embedding compassion within... [an] organization', why, how and the associated implications - be they intended or unintended? Although this special issue illuminates 'relational-centred care' (Kippist, Fulop, Dadich, \& Smyth, 2019), there is now opportunity to examine its other manifestations, as well as the parameters that demarcate 'high-quality connections and relational coordination'. This might involve the use of innovative methodologies - like POSH-VRE - given its demonstrated value when 'navigat[ing] complex... organisations' (Dadich, Collier, \& Hodgins, 2019).

Beyond these specific opportunities lie broader questions to pursue, to ultimately further POSH. For instance, although some 'patients, carers, and staff members... [have not] questioned what 
brilliance meant in their context or how to define it', what additional approaches might enable POSH to denote importance, compassion and care? How might the seismic wave of seeming pessimism in health service management discourse be redressed - particularly within the mass media, social media, government and international organisations? Additionally, given the new public management of healthcare and, relatedly, heightened interest in accountability and surveillance, how might POSH inspire evaluation designs that 'spark... positive interactions' (Brown, McNamara, O'Hara, \& Shevlin, 2019: 1)? And what are the intended and unintended effects associated with a positive orientation towards health service management - whether they are for the service, the staff therein, the consumers and carers they support, policymakers or scholars?

Through a critical lens is the opportunity to determine whether there can be 'too much positivity' (Spreitzer \& Cameron, 2012: 1042). There is also scope to clarify the full range of virtues to be considered within POSH, some of which remain largely neglected in research, such as 'wisdom, temperance, and transcendence' (p. 1043). In doing so, it would be helpful to know the methodologies and research methods that might be (in)appropriate for $\mathrm{POSH}$ - and how POSH might be used to embrace diverse traditions, rituals, values, genders, sexualities, races, religions and cultures (among others) and avert a 'monocultural tint' (p. 1042). Research is also required to clarify how government, health service and/or academic policies might support and promote $\mathrm{POSH}$, and the dark-side(s) of such policies.

These and other questions suggest there is considerable scope to advance POSH. As guest editors, we hope this special issue inspires you to step up to these challenges in preparation for, what we hope will culminate with, subsequent special issues dedicated to $\mathrm{POSH}$.

\section{References}

Alvesson, M., \& Kärreman, D. (2011). Qualitative research and theory development: Mystery as method. London: Sage Publications.

Alvesson, M., \& Sandberg, J. (2011). Generating research questions through problematization. Academy of Management Review, 36(2), 247-271.

Alvesson, M., \& Sandberg, J. (2012). Has management studies lost its way? Ideas for more imaginative and innovative research. Journal of Management Studies, 50(1), 128-152.

Anonymous. (2019). Instructions for contributors [Website]. Retrieved from http://journals.cambridge.org/action/ displaySpecialPage?pageId $=6780$

Australian Broadcasting Corporation (ABC) 7.30. (2018). ICAC finds patients were forgotten or given an abysmal level of care at Oakden Aged Care Home [Website]. Retrieved from https://www.abc.net.au/7.30/icac-finds-patients-were-forgotten-orgiven-an/9495220

Barker Caza, B., \& Caza, A. (2008). Positive organizational scholarship: A critical theory perspective. Journal of Management Inquiry, 17(1), 21-33.

Baxter, R., Taylor, N., Kellar, I., \& Lawton, R. (2016). What methods are used to apply positive deviance within healthcare organisations? A systematic review. BMJ Quality \& Safety, 25(3), 190-201.

Braithwaite, J., Wears, R. L., \& Hollnagel, E. (2015). Resilient health care: Turning patient safety on its head. International Journal for Quality in Health Care, 27(5), 418-420.

Bright, D. S., \& Miller, M. T. (2013). Appreciative inquiry and positive organizational scholarship: A philosophy of practice for turbulent times. In J. Vogelsang, M. Townsend, M. Minahan, D. Jamieson, J. Vogel, A. Viets, C. Royal, \& C. Valek (Eds.), Handbook for strategic HR: Best practices in organization development from the OD network (pp. 399-410). New York, NY: American Management Association.

Brown, M., McNamara, G., O’Hara, J., \& Shevlin, P. (2019). Polycentric inspection: A catalyst for sparking positive interactions in educational networks. Evaluation, Epub-ahead-of-print, 1-22.

Brunetto, Y., Dick, T., Xerri, M., \& Cully, A. (2019). Building capacity in the healthcare sector: A strengths-based approach for increasing employees' well-being and organisational resilience. Journal of Management \& Organization, Epub-ahead-of-print, 1-9.

Brunetto, Y., Xerri, M., Farr-Wharton, B., Shacklock, K., Farr-Wharton, R., \& Trinchero, E. (2016). Nurse safety outcomes: Old problem, new solution - The differentiating roles of nurses' psychological capital and managerial support. Journal of Advanced Nursing, Epub-ahead-of-print.

Burnie, R. (2019). Baked beans and mash Christmas 'slop' sparks social media outrage [Website]. Retrieved from https:// www.abc.net.au/radio/programs/am/baked-beans-and-mash-xmas-slop-sparks-social-media-outrage/11828412 
Cameron, K. (2008). Positive leadership: Strategies for extraordinary performance. San Francisco, CA: Berrett-Koehler Publishers.

Cameron, K. (2017). Paradox in positive organizational change. In W. K. Smith, M. W. Lewis, P. Jarzabkowski, \& A. Langley (Eds.), Oxford Handbook of organizational paradox (pp. 216-238). Oxford: Oxford University Press.

Cameron, K. S., \& Caza, A. (2004). Contributions to the discipline of positive organizational scholarship. American Behavioral Scientist, 47(6), 731-739.

Cameron, K. S., \& Spreitzer, G. M. (2012a). Introduction: What is positive about positive organizational scholarship? In K. S. Cameron \& G. M. Spreitzer (Eds.), Oxford Handbook of positive organizational scholarship (pp. 1-14). New York, NY: Oxford University Press.

Cameron, K. S., \& Spreitzer, G. M. (Eds.). (2012b). Oxford Handbook of positive organizational scholarship. New York, NY: Oxford University Press.

Cameron, K. S., Dutton, J. E., \& Quinn, R. E. (2003a). Foundations of positive organizational scholarship. In K. S. Cameron, J. E. Dutton, \& R. E. Quinn (Eds.), Positive organizational scholarship: Foundations of a new discipline (pp. 3-13). San Francisco, CA: Berrett-Koehler Publishers.

Cameron, K. S., Dutton, J. E., \& Quinn, R. E. (2003b). An introduction to positive organizational scholarship. In K. S. Cameron, J. E. Dutton, \& R. E. Quinn (Eds.), Positive organizational scholarship: Foundations of a new discipline (pp. 3-13). San Francisco: Berrett-Koehler.

Campbell, D. (2019). 10 English NHS hospital trusts overspend by $£ 850 \mathrm{~m}$ [Website]. Retrieved from https://www.theguardian.com/society/2019/may/10/10-english-nhs-hospital-trusts-overspend-by-850m.

Conroy, S. P., \& Turpin, S. (2016). New horizons: Urgent care for older people with frailty. Age and Ageing, 45(5), 577-584.

Crewe, S., \& Girardi, A. (2019). Nurse managers: Being deviant to make a difference. Journal of Management \& Organization, Epub-ahead-of-print.

Dadich, A., Collier, A., \& Hodgins, M. (2019). Navigating and understanding organisational complexity in health services: The value of POSH-VRE. Journal of Management \& Organization, Epub-ahead-of-print.

Dadich, A., Collier, A., Hodgins, M., \& Crawford, G. (2018). Using POSH VRE to examine positive deviance to new public management in healthcare. Qualitative Health Research, 28(8), 1203-1216.

Dadich, A., Fulop, L., Ditton, M., Campbell, S., Curry, J., Eljiz, K., ... Smyth, A. (2015). Finding brilliance using positive organizational scholarship in healthcare. Journal of Health Organization and Management, 29(6), 750-777.

Dutton, J. E., \& Sonenshein, S. (2007). Positive organizational scholarship. In S. Lopez \& A. Beauchamps (Eds.), Encyclopedia of positive psychology (pp. 737-742). Malden, MA: Blackwell Publishing.

Grant, A. (2014). Tufts medical center treats PATIENTS like SH*T! \#PoorHealthCare \#hospital \#discrimination [Website]. Retrieved from https://twitter.com/astronglady/status/441941076711321600.

Grant, S., \& Humphries, M. (2006). Critical evaluation of appreciative inquiry: Bridging an apparent paradox. Action Research, 4(4), 401-418.

Health and Social Care Committee, \& Housing Communities and Local Government Committee. (2018). Long term funding of adult social care inquiry. London: House of Commons. Retrieved from https://www.abuseincare.org.nz/.

Ion, R., Olivier, S., \& Darbyshire, P. (2019). Failure to report poor care as a breach of moral and professional expectation. Nursing Inquiry, 26(3), 1-9.

Kim, Y., Lee, E., \& Lee, H. (2019). Association between workplace bullying and burnout, professional quality of life, and turnover intention among clinical nurses. PLoS ONE, 14(12), 1-13.

Kippist, L., Fulop, L., Dadich, A., \& Smyth, A. (2019). Brilliant renal care: A really positive study of patient, carer, and staff experiences within an Australian health service. Journal of Management \& Organization, Epub-ahead-of-print, 1-20.

Luthans, F. (2002). Positive organizational behavior. Academy of Management Review, 16(1), 57-72.

Miller, E., Devlin, N., Buys, L., \& Donoghue, G. (2019). The happiness initiative: Changing organizational culture to make 'brilliance' mainstream in aged care. Journal of Management \& Organization, Epub-ahead-of-print, 1-13.

Nilsson, W. (2015). Positive institutional work: Exploring institutional work through the lens of positive organizational scholarship. Academy of Management Review, 40(3), 370-398.

Oliver, C. (2005). Critical appreciative inquiry as intervention in organisational discourse. In E. Peck (Ed.), Organisational development in healthcare: Approaches, innovations, achievements (pp. 205-218). Oxon: Radcliffe Publishing.

Palmer, V. J., Weavell, W., Callander, R., Piper, D., Richard, L., Maher, L., ... Robert, G. (2019). The participatory Zeitgeist: An explanatory theoretical model of change in an era of coproduction and codesign in healthcare improvement. BMJ Open Quality, 45(3), 247-257.

Quinn, R. E., \& Cameron, K. S. (2019). Positive organizational scholarship and agents of change. In A. B. R. Shani \& D. A. Noumair (Eds.), Research in organizational change and development (Vol. 27, pp. 31-57). Bingley: Emerald Publishing.

Roberts, R. (2017). Patients dying due to poor care, 'shocking' NHS report finds [Website]. Retrieved from https://www.independent.co.uk/news/uk/home-news/nhs-patients-dying-poor-care-emergency-oxygen-treatment-copd-a7844341.html.

Royal Commission into Aged Care Quality and Safety. (2019). Interim Report: Neglect. Adelaide, SA: Commonwealth of Australia.

Royal Commission of Inquiry. (2019). What is the inquiry about? [Website]. Retrieved from https://www.abuseincare.org.nz/. 
Simpson, A., \& Farr-Wharton, B. (2019). Cultivating organizational compassion in healthcare. Journal of Management \& Organization, Epub-ahead-of-print.

Spreitzer, G. M., \& Cameron, K. S. (2012). A path forward: Assessing progress and exploring core questions for the future of positive organizational scholarship. In K. S. Cameron \& G. M. Spreitzer (Eds.), Oxford Handbook of positive organizational scholarship (pp. 1034-1048). New York, NY: Oxford University Press.

Spreitzer, G. M., \& Sonenshein, S. (2003). Positive deviance and extraordinary organizing. In K. Cameron, J. Dutton, \& R. Quinn (Eds.), Positive organizational scholarship: Foundations of a new discipline (pp. 207-224). San Francisco: Berrett-Koehler.

Steffy, B. D., \& Grimes, A. J. (1986). A critical theory of organization science. Academy of Management Review, 11, 322-336.

Stewart, R. E., Williams, N., Byeon, Y. V., Buttenheim, A., Sridharan, S., Zentgraf, K., ... Beidas, R. S. (2019). The clinician crowdsourcing challenge: Using participatory design to seed implementation strategies. Implementation Science, 14(63), 1-8.

Studer Group. (2007). What's right in health care: 365 stories of purpose, worthwhile work, and making a difference. Gulf Breeze, FL: Fire Starter Publishing.

Tourish, D. (2019). The triumph of nonsense in management studies. Academy of Management Learning \& Education, Epub-ahead-of-print.

Waters Robichau, R. (2017). The intersection of positive organizational scholarship and organizational change. In P. Kraeger, S. Cloutier, \& C. Talmage (Eds.), New dimensions in community well-being (pp. 231-254).

WHO (World Health Organization). (2011). Global health and ageing. Geneva: WHO (World Health Organization).

WHO (World Health Organization). (2019). International crises [Website]. Retrieved from https://www.who.int/hac/crises/ international/en/.

Cite this article: Dadich A, Farr-Wharton B (2020). Positive organisational scholarship in healthcare. Journal of Management \& Organization 26, 289-295. https://doi.org/10.1017/jmo.2020.6 